\title{
Um dia particular na vida das criadas em Veneza segundo Goldoni
}

\section{Christine Zurbach}

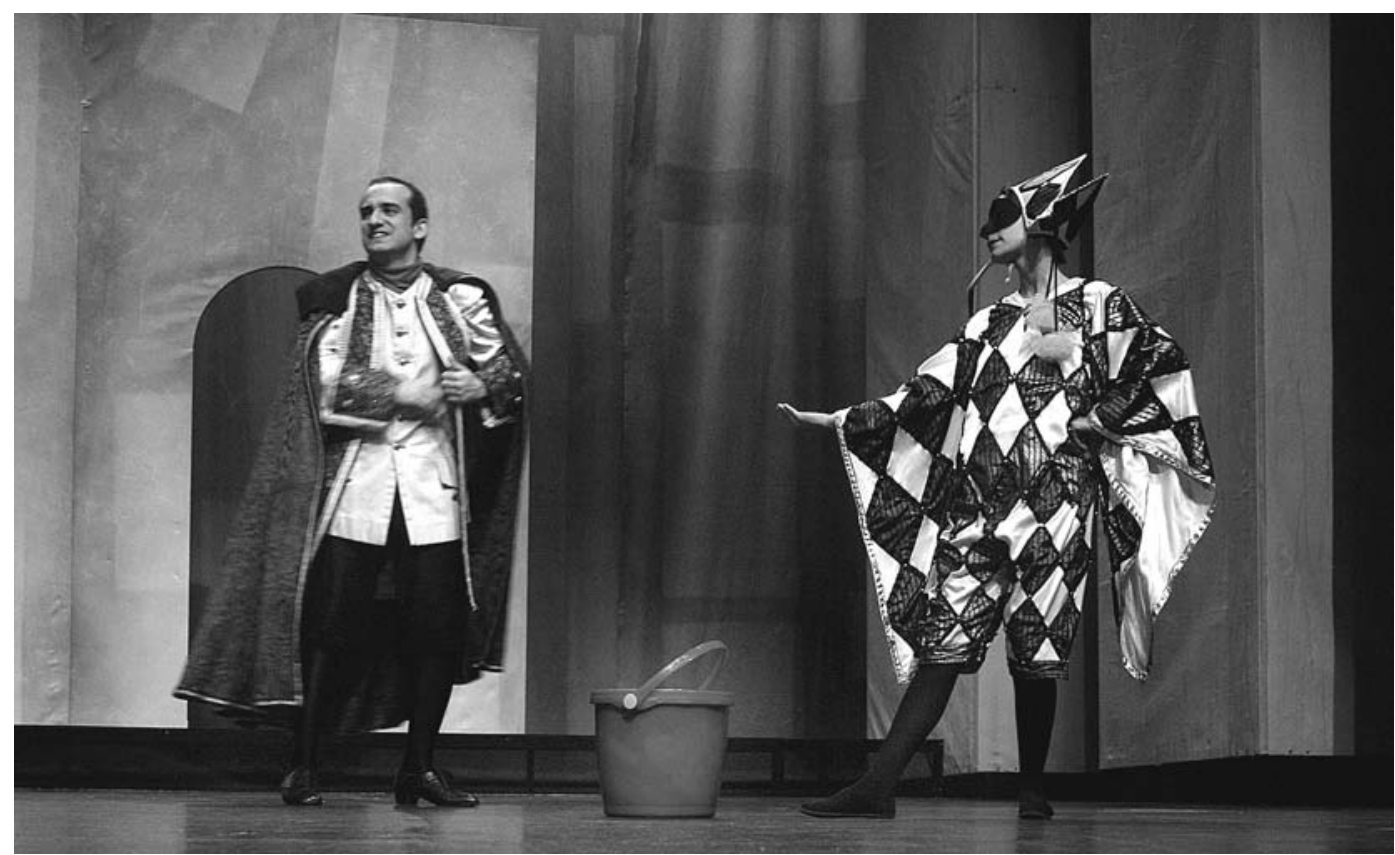

Criadas para todo o

serviço,

de Goldoni,

enc. José Peixoto,

Teatro Nacional D. Maria II / Teatro dos Aloés / Cendrev, 2007 (Luis Barros e Carla Carreiro Mendes), fot. Margarida Dias.

Titulo: Criadas para todo o serviço (Le nassare, 1755). Autor:Goldoni. Tradução: José Colaço Barreiros. Encenação: José Peixoto. Cenografia: Acácio Carvalho. Figurinos: Manuela Bronze. Luz: Carlos Gonçalves. Banda sonora: Rui Rebelo. Coreografia: Kot Kotecki. Intérpretes: Silvia Filipe, Jorge Silva, Elsa Valentim, Diana Costa e Silva, Ângela Ribeiro, David Pereira Bastos, Patricia André, Leonor Cabral, Luis Barros, Carlos Queirós, Ricardo Alves, Tiago Mateus, Carla Carreira Mendes. Co-produção:Teatro Nacional D. Maria II, Teatro dos Aloés e Cendrev. Local e data de estreia: Teatro Garcia de Resende, Évora, 1 de Março de 2007.

A peça do dramaturgo veneziano Carlo Goldoni (17071793) intitulada no original Le massere surge na recente encenação de José Peixoto em circunstâncias que justificam uma nota prévia. Com efeito, neste ano de 2007, o dramaturgo italiano é festejado em Portugal pela segunda vez em poucos anos no quadro de uma efeméride: após o bicentenário da sua morte em 1993, comemora-se agora o tricentenário do seu nascimento. Também é de assinalar que o evento associou o Teatro Nacional, o Teatro dos Aloés e o Cendrev, três agentes culturais com relevância na vida teatral portuguesa, e sobretudo, para os dois últimos, já experientes e com provas dadas na recepção de Goldoni em Portugal.

Segundo afirma nas suas Mémoires (II, 21), Goldoni escreveu a peça, uma das últimas antes da sua partida para Paris em 1762, para "divertir"o público de Veneza nos últimos dias da semana do Carnaval de 1755 e, também, para agradecer o bom acolhimento dado à sua La Madre amorosa, uma comédia "séria" levada à cena pouco antes pela companhia veneziana de San Luca que o contratara em 1753. "Divertir" o público com uma comédia, não significa, todavia, que se trate de um divertimento no sentido da ligeireza geralmente associada ao termo. Na ocorrência, o autor pretende designar um texto cujo tema deverá interessar o seu público por se tratar de um assunto diferente da peça anterior. Nele retoma a tradição que ele próprio criou, a de pôr em cena as classes populares, que falam na sua língua natural, o dialecto veneziano. Como é sabido, o conceito de comédia segundo Goldoni visava, desde 1743, reformar o teatro cómico, substituindo o improviso praticado até então pelos actores dell'arte por diálogos escritos, sendo nisso devedor do modelo francês de Molière de que se apropria de maneira criativa em prol de um teatro sério, digno da época das Luzes. A busca do natural na representação do quotidiano permitia ao dramaturgo evocar vícios e virtudes das classes populares, que também são espectadoras desse mesmo teatro onde se vêem retratadas de maneira realista, 


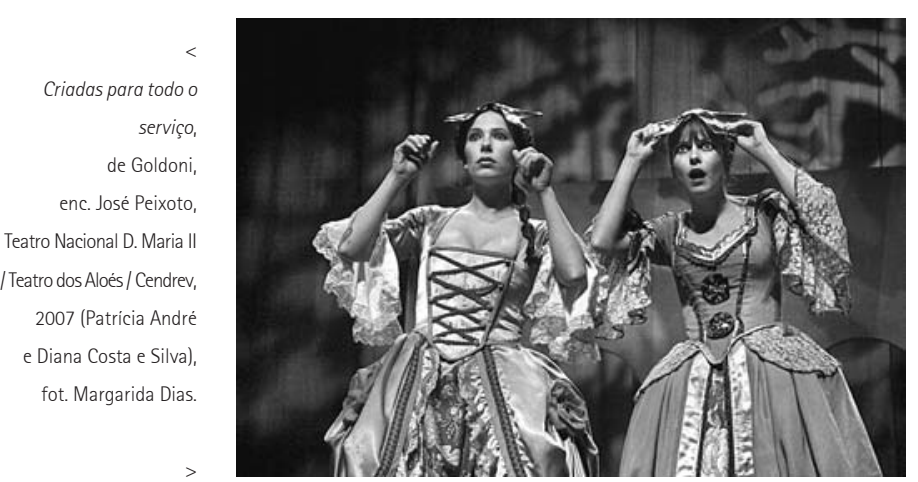

Criadas para todo o

enc. José Peixoto, Teatro Nacional D. Maria /Teatro dos Aloés / Cendrev 2007 (Diana Costa e Silva

e Elsa Valentim) fot. Margarida Dias.

Criadas para todo 0

enc. José Peixoto, Teatro Nacional D. Maria /Teatro dos Aloés / Cendrev,

2007 (Patrícia André,

Luis Barros

e Diana Costa e Silva),

fot. Margarida Dias.

Carlo Goldoni,

Criadas para todo serviço, trad. José Colaço Barreiros, Teatro Naciona D. Maria II, Lisboa, 2007. tanto nas suas acções como na sua linguagem, mas sem elogios nem condenações abstractas, apenas na vivência complexa que define as relações de serviço numa sociedade fortemente hierarquizada. É nessa finalidade que reside a chave ética e moral da peça.

Nesse ponto, a tradução portuguesa ${ }^{1}$ do título - que, no fundo, constitui a primeira janela sobre o sentido do texto - privilegiou uma conotação da condição das criadas algo desviante relativamente ao projecto reformador de Goldoni, trazendo conotações hoje associadas a um modelo "vaudevilesco" da expressão "para todo o serviço", em particular no que toca à vertente oculta da vida privada

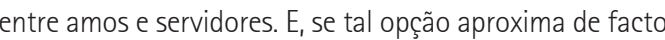
as criadas goldonianas de uma imagem banalizada e recorrente da sua condição na literatura oitocentista, também oculta um lado profundamente negro da realidade das relações no serviço doméstico aqui retratado e que o colorido cor-de-rosa e apaziguador do cartaz do espectáculo poderia desmentir.

A tradução propõe igualmente actualizações linguisticas que aproximam o texto do destinatário, condizendo com as opções de cenografia e guarda-roupa. De facto, do mesmo modo que com a língua, o espaço, o tempo, os adereços e também a música, a encenação recorre à modernização dos sinais utilizados que, mesclados com referências históricas setecentistas, acabam por instalar um quadro de referências histórico-sociais algo atemporais. Ao contrário da imagem previsivel do burguês de peruca branca que vive no nosso imaginário cultural sobre tais peças, os figurinos procuram associar na cor, nos tecidos e no corte temporalidades distantes que se conjugam e recompõem reciprocamente. Também na cena inicial, um adereço como o balde para a água é não só vermelho como feito de plástico, tornando-se central no arranjo da cena em que joga com algum erotismo com a capa
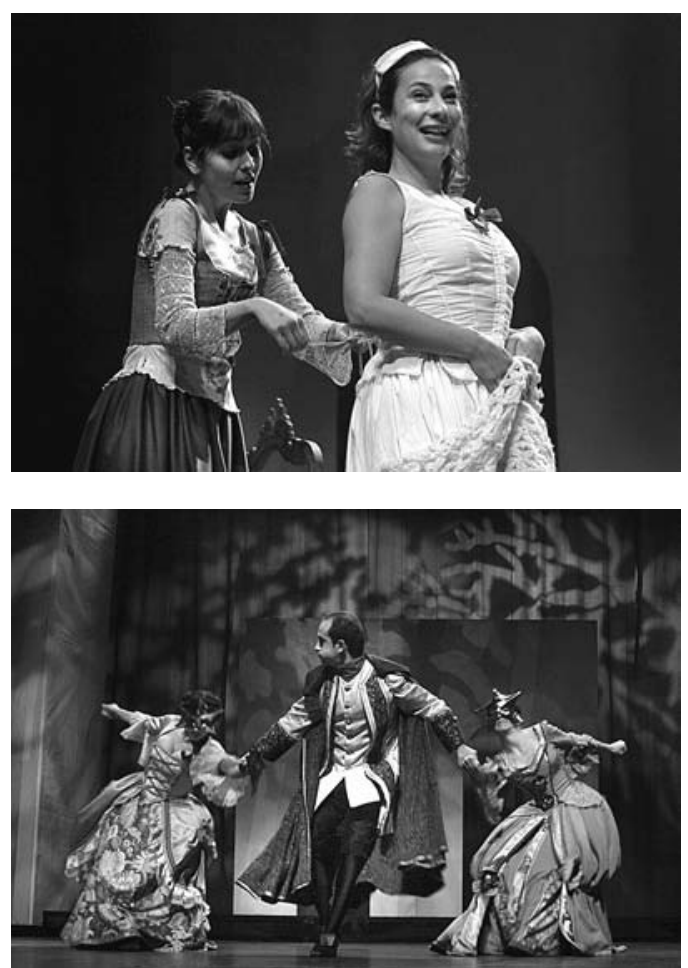

veneziana típica de Anzoletto, o jovem empregado de loja em busca de divertimento gratuito (nos dois sentidos da palavra) com as criadas nesse dia prometedor.

Com o título italiano Le massere, o texto anuncia um tema goldoniano privilegiado: o da condição das mulheres que, no título em francês dado pelo próprio Goldoni, Les Cuisinières, inequivocamente, são a figuração no teatro, não das criadas de quarto, as suivantes da comédia clássica, mas de quem pertence à camada dos servidores a quem incumbe o trabalho doméstico na sua dimensão física, manual, cuja realidade concreta é, aliás, insistente na peça. A cena inicial mostra de forma abrupta a dureza da sua condição e é construída em torno de dois temas com um valor algo simbólico: fazer o pão que será entregue logo ao nascer do dia (num Inverno particularmente frio nesse ano) ao moço de padeiro, Momolo; cuidar de que não falte a água potável, um bem precioso em Veneza. Também, como Meneghina, passam fome e frio quando os patrões descuidam as suas obrigações. No entanto, se a peça é um retrato da dureza da vida dessas criadas, elas não são mostradas como vitimas passivas: mentem, roubam e enganam os patrões, sem hesitar nos meios, tanto mais 
que a intriga principal é situada no dia que lhes era inteiramente concedido durante o Carnaval para se divertirem e se mascararem. Mas tal vontade, afirmada repetidamente pelas personagens, amos e criados, constitui o factor (pontual e acrescido) dos conflitos com os amos que procuram privar as beneficiárias desse raro privilégio.

A dramaturgia de Goldoni é, não raramente, associada a um espaço e um tempo marcados pelo espaço de Veneza, e pelo seu Carnaval. Mas se Veneza é aqui figurada, enquanto proposta cenográfica e ambiente luminoso, na sua beleza de cidade prestigiada e a mais deliciosa para nela se viver, passa progressivamente para uma espécie de inferno. Do mesmo modo, o Carnaval, época de todas as inversões, dando acesso ao prazer e à alegria mais gratuita, também comporta gestos da mais negra crueldade. É nesse quadro que são expostos o sórdido e a alienação das mulheres "para todo o serviço". Sendo um dado essencial da leitura do encenador, o Carnaval é patente na vivacidade do ritmo dado à peça pelo jogo dos actores, com destaque para as actrizes nas figuras muito expressivas das quatro criadas. É nelas que se exprime a busca frenética da felicidade possivel nesse momento de festa, de um só dia, que Ihes é concedido para andarem livremente, como diabos à solta. Assemelham-se nisso aos dois amos velhos e ricos - uns autênticos tiranos libidinosos ainda que ridículos - que parasitam, também com Anzoletto, a festa das mulheres mascaradas que, por sua vez, Ihes pagam na mesma moeda, comendo e bebendo por conta deles.

A encenação serve a vocação profundamente teatral desse teatro e, nesse sntido, recorre subtilmente a evocações do estilo gestual dell'arte em dois apontamentos: toda a movimentação do moço de padeiro na cena de abertura e a breve passagem de um Arlequim bem sinalizado. Mas também, opta por uma dramaturgia que defende a oposição estruturante da fábula, entre o realismo inicial (num ambiente acertadamente enevoado criado na sala do espectáculo) do trabalho quotidiano das criadas nos dois actos de exposição e a fantasia dos três actos seguintes, inscritos no mundo festivo do Carnaval, entremeado com cenas em torno da tentativa de sedução de Dona Dorotea, uma burguesa viciada no jogo, pelo senhor Raimondo seu vizinho, marido da infeliz Dona Constanza, a troco de um anel que a criada trata de desviar em seu proveito próprio. Esta é uma entre as muitas partidas que as cozinheiras pregam aos seus patrões em resposta à violência inerente às relações que com eles tecem. Mas a usurpação do fato e do nome da ama Dorotea por Meneghina, a pedido da velha criada Rósega, não terá perdão, apesar dos possiveis do Carnaval. Desmascaradas no fim, as criadas são despedidas e o Carnaval surge como triste metáfora sem alegria da sua condição e também da imoralidade dos seus patrões.

Além do jogo conotativo implícito no título português, o final do espectáculo também se distancia desse discurso inequivocamente pessimista do dramaturgo. Goldoni assume uma posição de condenação moral do comportamento abusivo das quatro criadas, sancionado no termo das peripécias que protagonizaram durante a jornada de Carnaval. Mas na questão de se saber se são boas ou más, o dramaturgo responde com uma igual condenação da dissolução dos costumes no mundo dos patrões, insistentemente reflectido ao longo da peça no discurso das criadas, nomeadamente quando evocam o vício tão veneziano do jogo ou as relações conjugais: o espectador é informado, por exemplo, dos maus-tratos infligidos à patroa de Meneghina pelo marido que também a priva de comida; ou ainda, presencia a tentativa de sedução de Dorotea por Raimondo, casado com uma Constanza desequilibrada pelo ciúme (e pela paixão numa versão extremada de cantora de ópera). No texto original é à mesma Constanza, mulher enganada pelo marido, a quem, ironicamente, compete assumir a palavra final, e separar criadas boas e más, porque de facto, essas, também existem... Pelo contrário, na versão agora posta em cena, o encenador pôs na boca de Anzoletto um texto novo, que comenta a posição do autor-fonte, mas que também apresenta uma posição extremamente conciliadora, e prefere nessa última fala introduzir um perdão às criadas, sem censura. Todavia a hipocrisia que domina no mundo dos patrões, na peça e na realidade, acaba por ficar na sombra sem poder surgir em contraponto. No entanto, o Carnaval terá servido como revelador da violência de dois universos, num relacionamento pautado por uma dependência recíproca na realidade do espaço da vida doméstica entre amos e servidores, e também entre marido e mulher, na sua dimensão oculta, partilhada dentro das casas, e agora exposta na praça pública e na verbalização nas queixas de ambos os grupos sobre o outro.

Interpretar Criadas para todo o serviço como um divertimento foi o ponto de partida desta encenação que fez escolhas assumidas nos diversos planos da construção de um objecto essencialmente teatral, coerentemente preocupado com a qualidade artística que não surpreende da parte de um dos poucos encenadores que, em Portugal, aceitaram relevar os desafios postos pela dramaturgia goldoniana a um espectador do nosso tempo. 